\title{
Teorías de liderazgo contemporáneo: análisis de la dinámica relacional
}

\section{Contemporary leadership theories: analysis of relational dynamics}

\section{Teorias de liderança contemporânea: análise das dinâmicas relacionais}

\author{
Soraya Elizabeth Sánchez Montalván \\ Iván Patricio Vaca Aguirre* \\ Juan Pablo Padilla Sánchez \\ Claudio René Quezada Condolo
}

\section{RESUMEN}

El liderazgo como capacidad de influencia, intercambio y contribución entre líder y sujetos, constituye un elemento decisor en la producción de vínculos y relaciones entre los distintos actores. El artículo describe las principales teorías de liderazgo con énfasis en planteamientos conceptuales contemporáneos. Mediante la respuesta a ¿cómo incide la dinámica relacional en los modelos de liderazgo contemporáneos?, se interpretan relaciones de influencia, de intercambio y la incidencia de las motivaciones para establecer la correspondencia con modelos de liderazgo relacional como posibles enfoques teóricos en la economía popular y solidaria.

Palabras clave: liderazgo, influencia social, comportamiento organizacional, motivación.

\section{ABSTRACT}

Leadership as an ability to influence, contribute and exchange something between people and their leaders, it is a deciding element in the production of links and relations between different

Ecuatoriana, Magíster en Administración de Empresas, Diplomado Superior en Gerencia de Marketing, Diploma Superior en Formación de Formadores en Responsabilidad Social Empresarial, Ingeniera en Gerencia y Liderazgo, Profesora Investigadora, Universidad Politécnica Salesiana, Sede Quito, Ecuador. Correspondencia con la autora: ssanchezmontalvan@yahoo.es, ssanchez@ups.edu.ec.

** Ecuatoriano, Licenciado en Estadística, Magíster en Gestión en Contabilidad y Finanzas, Especialista Superior en Creación de Empresas, Profesor Investigador, Universidad Politécnica Salesiana de Quito, Ecuador. Correspondencia con el autor: ivacaa@ups.edu.ec, ivaca57@hotmail.com.

${ }^{* * *}$ Ecuatoriano, Licenciado en Ciencias de la Educación, Ingeniero en Gerencia y Liderazgo, Profesor Investigador, Universidad Politécnica Salesiana. Correspondencia con el autor: jpadillas@ups.edu.ec.

Ecuatoriano, Licenciado en Ciencias de la Educación, Especialidad Física y Matemática, Magíster en Docencia Matemática, Profesor Investigador, Universidad Politécnica Salesiana de Quito, Ecuador. Correspondencia con el autor: cquezadac@ups.edu.ec, renequezad@ yahoo.com. 
actors. The article describes the main leadership theories with an emphasis on contemporary conceptual approaches. By answering: "How does relational dynamics affect contemporary models of leadership?, interpreted influence relationships, exchange and incidence of motivations for mapping relational models of leadership are interpreted as possible theoretical approaches in popular and solidary economy.

Keywords: leadership, social influence, organizational behavior, motivation.

\section{RESUMO}

A liderança como capacidade de influencia e contribuição entrelíder e indivíduos, constitui um elemento decisivo na produção de vínculos e relaçóes entre os diferentes atores. $\mathrm{O}$ artigo descreve as principais teorias de liderança com ênfase em abordagens conceituais contemporâneos. Através da resposta de Como afeta a dinâmica relacional em modelos contemporâneos de liderança? , interpretam-se relaçóes de influência, de intercâmbio e a incidência das motivaçóes para estabelecer a correspondência com modelos de liderança relacional como possível abordagem teórico na economia popular e solidaria.

Palavras-chave: liderança, influência social, comportamento organizacional, motivação.

\section{Introducción}

Debido a las características de complejidad y diversidad en la conceptualización del liderazgo, se han generado diferentes corrientes teóricas y perspectivas, en base a variables que han identificado las características personales del líder o de acuerdo a su relación con los subordinados o colaboradores. Al respecto Kroeck, Lowe \& Brown (2004), citados por Lupino \& Castro (2005), señalan: "El campo constituido por el liderazgo es muy diverso e incluye un amplio espectro de teorías, definiciones, evaluaciones, descripciones, prescripciones y filosofías, [...] son muchas las escuelas u orientaciones teóricas que abordaron el análisis de dicho constructo" (Lupano Perugini \& Castro Solano, 2005:108).

En este sentido, Mouse y Aditya (1997) sintetizan en cuatro principales corrientes teóricas el desarrollo de los estudios de dirección y liderazgo. 
Cuadro 1. Principales corrientes de liderazgo

\begin{tabular}{|c|c|c|}
\hline TEORÍAS & ORIENTACIÓN & $\begin{array}{l}\text { PRINCIPALES } \\
\text { AUTORES }\end{array}$ \\
\hline Rasgos & $\begin{array}{l}\text { Determinar características y habilidades } \\
\text { distintivas del líder que explican la eficiencia } \\
\text { del liderazgo. Enfoque funcionalista. }\end{array}$ & $\begin{array}{l}\text { *Ralph Stogdill } \\
{ }^{*} \text { McCall y Lombardo }\end{array}$ \\
\hline Comportamiento & $\begin{array}{l}\text { Explicar los estilos distintivos de los líderes o } \\
\text { definir la naturaleza de su labor y elementos } \\
\text { conductuales. Dirigir con ejemplo. }\end{array}$ & $\begin{array}{l}\text { *McGregor } \\
\text { *Lewin } \\
{ }^{*} \text { Likert } \\
\text { *Blake y Mounton }\end{array}$ \\
\hline $\begin{array}{l}\text { Contingencia/ } \\
\text { situacional }\end{array}$ & $\begin{array}{l}\text { Reconocer y adaptarse a la naturaleza de la } \\
\text { situación y demandas de colaboradores. Actuar } \\
\text { en función a situaciones. }\end{array}$ & $\begin{array}{l}\text { *Fiedler } \\
\text { *Hersey y Blanchard }\end{array}$ \\
\hline Integral/emergente & $\begin{array}{l}\text { Explicar por qué son fructíferas las relaciones } \\
\text { de influencia e intercambio entre líderes y } \\
\text { seguidores. Nuevas perspectivas. }\end{array}$ & $\begin{array}{l}\text { *Burns } \\
{ }^{*} \text { Bass/ Avolio } \\
{ }^{*} \text { Crossan, Vera, Nanjad } \\
{ }^{*} \text { Goleman }\end{array}$ \\
\hline
\end{tabular}

Fuente: adaptado de Sánchez Manchola (2008).

Por su parte Ascorra (2008), en su propuesta para la comprensión de modelos y teorías sobre liderazgo, refiriéndose a la complejidad y diversidad de información existente sobre liderazgo, con el objeto de reducir su multiplicidad, propone dos variables que estructuran los modelos y teorías actuales sobre liderazgo: la primera con referencia al origen del liderazgo a partir de posiciones esencialistas y no esencialistas ${ }^{1}$. La segunda se relaciona con

[...] la comprensión de lo social, supuesta en los modelos y teorías. En este caso, es posible distinguir teorías que privilegian el impacto que tendrían las variables individuales en los procesos sociales (teorías con énfasis en lo individual); otras, que privilegian la interacción entre variables del individuo y de la situación (interaccionales) y, finalmente aquellas que conciben lo social como el producto de las relaciones que se producen entre los sujetos (relacionales) (Ascorra Costa, 2008:62).

En referencia a la comprensión de lo social, los modelos contemporáneos categorizan el liderazgo basado en las habilidades del líder para motivar a sus seguidores

1 Entiéndase por esencialistas los modelos centrados en rasgos universales como características unipersonales del líder, mientras los no esencialistas hacen énfasis en características del entorno y contexto social e histórico. 
a intervenir en la dinámica organizacional a través de sus competencias, comportamientos e iniciativas que van más allá de sus intereses personales. Cetina et al. (2010), al referirse a lo relacional, agrupan el liderazgo en carismático, transaccional y transformacional.

Con relación a estas teorías que conciben lo social como el producto de las relaciones entre los sujetos, denominadas relacionales, Ruiz Palomino (2009) refiere:

[...] al considerar que el colaborador es importante en el proceso de liderazgo, la investigación comenzó a tener en cuenta otra perspectiva a la hora de afrontar y entender este fenómeno. Este nuevo enfoque centra su interés en la importancia del papel desempeñado por el colaborador, y en consecuencia, en comprender las expectativas de éste sobre la relación y en mejorar la relación que se da entre el líder y el colaborador (Ruiz Palomino, 2009:7).

Estas consideraciones conducen a concluir en el gráfico 1 una categorización basada en el nivel de relación, donde determinadas corrientes tienen una extendida trayectoria de investigación y se centran en el líder, mientras que otras identifican características del liderazgo relacional, "el comportamiento del líder en este caso pretende fortalecer la cohesión del grupo. Por lo tanto, se orientará hacia las personas, sus satisfacciones como individuos y como grupo, su pertenencia, adhesión al grupo y sus objetivos" (Zayas \& Cabrera, 2006:53). Estos autores contemplan dentro de esta orientación a tipos de liderazgo como transaccional, transformacional y trascendente.

\section{Metodología}

La metodología se plantea en dos fases, utilizando para la investigación fuentes secundarias de información, con la finalidad de sustentar conceptualmente las principales teorías de liderazgo contemporáneo y establecer la dinámica relacional.

Primero, para identificar los modelos de liderazgo contemporáneo, se realizó una minuciosa revisión de la bibliografía académica sobre liderazgo, siguiendola estrategia de selección de artículos diseñada por De Bakker et al. (2005), con un recorrido por las bases de datos académicas Google Académico, Bibliotecnia, ProQuest y EBSCO. La depuración consideró trabajos publicados entre el año 1950 y 2013, que involucra las palabras "liderazgo", "relacional", "modelos" y "economía solidaria", llegando a considerarse 233 publicaciones entre libros y artículos, y 29 filtraron como cardinales para este objetivo, identificadas por la propia literatura como claves para la disciplina; además se han utilizado todas las publicaciones periódicas de la Superintendencia de Economía Popular y Solidaria de Ecuador. 
Gráfico 1. Categorización de los modelos de liderazgo.

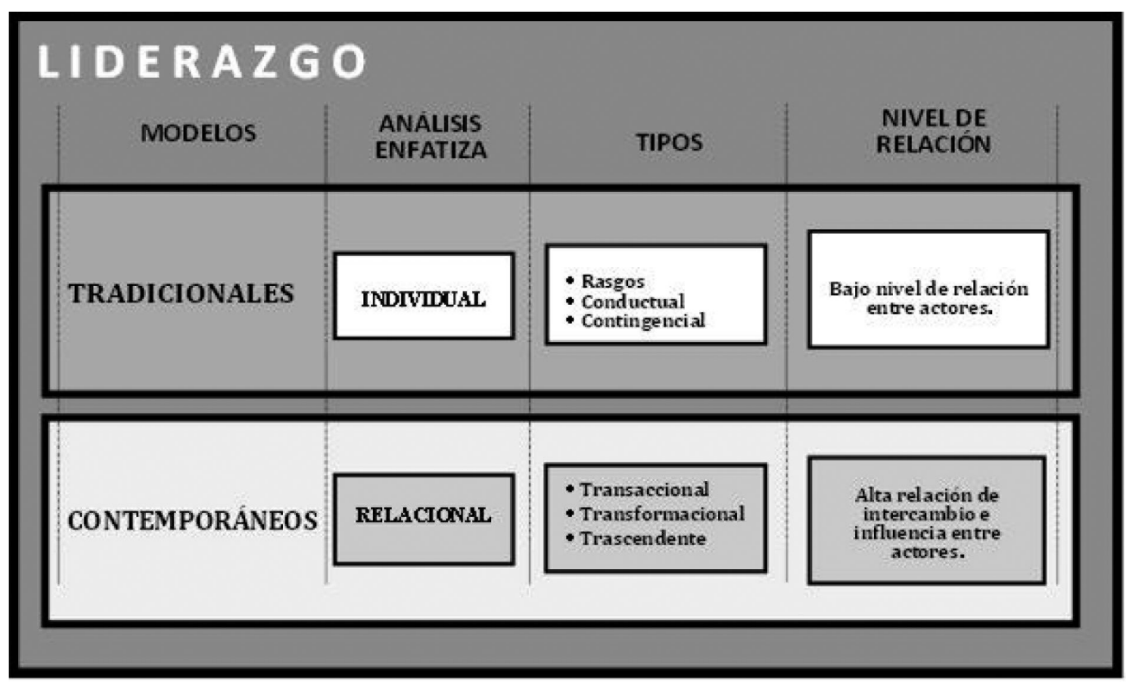

Fuente: elaboración propia.

La segunda fase metodológica, consistió en encontrar respuesta a la formulación de la interrogante planteada: ¿Cómo incide la dinámica relacional en los modelos de liderazgo contemporáneos?, con la finalidad de analizar la incidencia de la dinámica relacional y determinar las relaciones de intercambio e influencia en los modelos de liderazgo transaccional, transformador y trascendente. Finalmente se redactaron las conclusiones obtenidas dentro de una discusión.

En este contexto, el objetivo de este artículo es revisar las principales teorías de liderazgo, haciendo énfasis en los planteamientos conceptuales contemporáneos para de esta forma establecer la correspondencia entre la lógica relacional y los modelos de liderazgo transaccional, transformacional y trascendente.

A continuación, en primera instancia, se describen tres enfoques de liderazgo que concibe este análisis como relacional, por ser definitorias las peculiaridades de intercambio e influencia que se dan en ellos, para una aplicación en organizaciones de economía popular y solidaria: luego, en la discusión se analiza la dinámica relacional en los modelos de liderazgo contemporáneos.

\section{Liderazgo transaccional}

Definido por una relación de influencia de tipo económico. "En esta relación el colaborador interactúa con el líder únicamente por motivación extrínseca” (Cardona, 
2000:7). "Los líderes transaccionales exhiben comportamientos asociados a transacciones constructivas y correctivas. El estilo constructivo es llamado recompensa contingente y el estilo correctivo gerencia por la excepción" (D’Alesio, 2010:61).

El papel fundamental del líder en el liderazgo transaccional, es lograr las metas y cumplir con los objetivos en una dinámica laboral de trabajar bajo presión; es decir, mantener la eficiencia y evitar cometer errores en el cumplimiento de las actividades. En este modelo de liderazgo, la base es el cumplimiento de objetivos a través de un intercambio de premios y castigos. Todo esto conlleva a que este liderazgo esté basado en un tipo de condicionamiento operante de estímulo-respuesta.

Para Rice (1997), el condicionamiento operante consiste en aprender de las consecuencias de la conducta, destacando que de acuerdo con Skinner (1904-1990), la conducta opera en el ambiente para producir consecuencias, que pueden ser recompensas o castigos.

Por lo tanto, la dinámica del liderazgo transaccional consiste en condicionar al colaborador para que cumpla las metas. En las empresas principalmente se aplica cuando se necesita llegar a objetivos específicos de calidad y en tiempos establecidos.

El liderazgo transaccional, implica cuatro dimensiones: recompensa o refuerzo contingente, gestión activa por excepción, gestión pasiva por excepción y laissez - faire.

En la dimensión de recompensas o refuerzo contingente, el líder transaccional establece una relación del objetivo con la recompensa, pone de manifiesto las expectativas, entrega los recursos a los seguidores, establece objetivos por consenso, específicos, medibles, realistas, a ejecutarse en un tiempo determinado, y asigna varios tipos de recompensas por un desempeño exitoso.

En la gestión activa por excepción, el líder transaccional controla el trabajo de sus subordinados, verifica desviaciones a las reglas y aplica acciones correctivas para prevenir errores. Mientras que en la gestión pasiva por excepción, el líder transaccional interviene solo cuando el resultado no es el esperado.

Finalmente, en la dimensión de laissez - faire, el líder provee de un entorno donde los subordinados cuentan con muchas herramientas disponibles para tomar decisiones. El líder no toma decisiones y el grupo carece de dirección.

En conclusión, se debe entender al liderazgo transaccional como una relación de intercambio de tipo económico, entre el líder y sus seguidores con motivación extrínseca, estableciendo parámetros que regulan las expectativas de cada una de las partes a cambio de un valor por el trabajo realizado, en concordancia con lo expresado por 
García (2010) en la investigación de Liderazgo transformacional y la facilitación de la aceptación al cambio organizacional.

\section{Liderazgo transformacional}

El liderazgo transformacional constituye una de las teorías de liderazgo que más se trabaja en la actualidad. Se define como una relación de influencia de tipo social con motivación intrínseca que propone el cambio del statu quo, la idea original, actual, por una visión de futuro que influencia a los seguidores a través de nuevas ideas.

El liderazgo transformacional se asocia con la idea de cambio en los entornos en que se aplica, pues la imagen del líder en esta teoría es conocida "por conmover y cambiar las cosas [...] al comunicar a los seguidores una visión especial del futuro, utilizando los ideales y motivos más altos de los seguidores" (Lussier \& Achua, 2011:348).

La función del líder "tiene un rol no delegable en la instrumentalización de un cambio, teniendo en cuenta elementos como la creación de una visión compartida [...]" (García Rubiano, 2011:44).

Un elemento fundamental de la teoría de liderazgo transformacional es el vínculo generado a través del compromiso -entre líder y seguidores- hacia la consecución de metas. La influencia que genera el líder sobre sus seguidores es lo que permite articular la visión de grupo y proyectarse al logro de objetivos comunes.

"El liderazgo transformacional es visto como el liderazgo "real" [los líderes transformacionales] procuran optimizar e innovar el desarrollo individual, grupal, y organizacional, y que no se quede solo en expectativas" (D'Alessio, 2010:60).

El convencimiento de los líderes a los seguidores juega un rol importante pues permite "inyectar" constantemente en el grupo presión por alcanzar las metas propuestas, viabilizando esfuerzos hacia el cumplimiento ético y moral.

Bernard Bass (1985), en su texto Leadership and performance beyond effectiveness, citado en D'Alessio (2010), hace una categorización de componentes que conforman el liderazgo transformacional.

Inicialmente menciona la influencia idealizada como ese conjunto de habilidades de los líderes para generar admiración, respeto y confianza. Su comportamiento basado en principios éticos y morales termina por convertirlos en modelo para sus seguidores. "Un punto a favor de estos líderes es que consideran las necesidades de sus seguidores por encima de sus propias necesidades" (D’Alessio, 2010:60). 
Por otro lado, se encuentra la motivación inspiracional ${ }^{2}$ como una acción específica que ejercen los líderes hacia su entorno, valorando y reconociendo el trabajo realizado por sus seguidores. Se visualiza así el nexo formado gracias al optimismo que transmite el líder a los demás, procurando alentar las acciones del grupo hacia una visión común construida.

La estimulación intelectual implica un nivel más alto de motivación y relación entre los actores en el proceso, tocando temas y realizando acciones que permitan retroalimentar a los colaboradores en sus funciones, generando proactividad.

Finalmente, la consideración individual como un factor de importancia al abordar el liderazgo transformacional, puesto que marca la cercanía entre el grupo y el líder por el interés de este último en el desarrollo de las personas, procurando su motivación y avance en un ambiente de estímulo constante, donde entran en juego incluso herramientas como mentoring y coaching.

Otro factor de importancia en el liderazgo transformacional es el carisma, que se basa en la influencia generada por el líder en sus seguidores; la relación que se genera está basada en la confianza, admiración y respeto que perciben -los otros- hacia este individuo.

Weber (1920) establece al carisma desde el concepto de dominación, en su texto Sociología de la dominación. Determina que el carisma no es sino "la cualidad [extraordinaria] de una persona considerada [...] por la que se considera que [...] está dotada de fuerzas o propiedades [...] no accesibles a cualquier persona" (Weber, 2007:35).

El carisma -y específicamente el liderazgo carismático- podría establecerse como un aspecto relacional que se genera entre el líder y el grupo; el primero presenta un conjunto de ideas articuladas como la visión de futuro y los objetivos que espera alcanzar en conjunto; mientras por el otro lado, se encuentra la interpretación de los seguidores y creencia que tales acciones y objetivos son alcanzables, más que por su lógica y racionalidad, por la confianza en las habilidades "únicas" de dicha figura "mesiánica" de líder.

En este sentido, se identifica la importancia de la cercanía entre el liderazgo transformacional y el carisma de los líderes, al definirlo como un aspecto de identidad, de confianza y relación directa entre las demandas del grupo y la construcción de visión generada por el líder.

2 Tanto la sub-área de influencia idealizada como la motivación inspiracional son unificadas posteriormente en la explicación del liderazgo carismático. 


\section{Liderazgo trascendente}

Teoría contemporánea del liderazgo, definido por una "[...] relación de influencia de contribución. En esta relación, el colaborador interactúa con el líder por motivación intrínseca [la ejecución de la acción le interesa por el beneficio que ésta le aporta], extrínseca [recompensa, algo a cambio de su tarea o gestión] y trascendente [motivación causada por la contribución de la acción en el desarrollo de los otros]" (Cardona, 2000:7).

Apostando por la línea teórica de relaciones de intercambio, algunos autores proponen sustitutos de liderazgo, que desafían la orientación convencional del comportamiento estratégico del líder, generando una amplia gama de habilidades específicas para manejar el dinamismo de entornos complejos con procesos de intercambio social, a través del desarrollo de tres niveles de liderazgo: personal, los demás, la organización.

Crossan et al. (2008) proporcionan una visión realista y alcanzable del fenómeno al analizar el liderazgo trascendente desde varios sustitutos de la influencia del líder en el rendimiento del subordinado y de la organización, encontrando que el liderazgo trascendente optimiza los talentos humanos y energías para el bien de todos.

La Academy of Management Annual Meeting Proceedings (2011), en su publicación Towards an expanded model of transcendent leadership: substitutes and the societal level, complementa la comprensión de los niveles del liderazgo trascendente tomando en cuenta la variable sociedad. Se sintetiza a continuación el aporte de esta publicación en lo relativo a los sustitutos por considerar que describe al liderazgo trascendente de manera razonable, circunscribiendo la realidad de los líderes en las organizaciones actuales.

Sustituto del liderazgo del nivel leadership of shelf, el líder tiene la capacidad de ser consciente de sí mismo; confiar en las propias motivaciones personales, en sus patrones de pensamiento y de autorregulación; así como la capacidad de alinear las características personales con las acciones de la organización. Los líderes con estas capacidades pueden darse cuenta de que necesitan ayuda en la dirección de su organización, ya que no tienen los requisitos necesarios para llevar a cabo determinada tarea. La adición de otra persona para crear un shared leadership pair puede enfatizar fortalezas de cada individuo y reducir al mínimo las debilidades.

Sustitutos del liderazgo del nivel otros, la capacidad de un líder para dirigir a la altura de los demás está sujeta a las competencias de sí mismo, de sus seguidores, los recursos y el apoyo en general. 
Este nivel plantea dos sustitutos, el primero implica un cambio de enfoque de los seguidores y la estructura organizacional, en consecuencia el líder debe facilitar un ambiente de trabajo basado en una cultura organizacional con las características necesarias para el desarrollo eficaz de los seguidores, donde se enfatice la unidad, la productividad y el empoderamiento como base de la estabilidad organizacional del presente y futuro; donde los empleados sean miembros con influencia, con conexión emocional compartida y con necesidades satisfechas. El segundo sustituto para este nivel es la selección de personal con competencias paralelas al líder en los cuatro niveles -personal, otros, organización y sociedad-, puesto que la organización requiere de personal que actúe de una manera cívica, siendo capaz de iniciar el cambio y ejercer influencia de contribución.

Sustitutos del liderazgo nivel de la organización, se describen responsabilidades que deben cumplirse: interpretar el entorno, elaborar la estrategia, facilitar la auto-organización, evitar ambigüedades con el rol particular del seguidor, articular una visión orientada a la organización y promover valores y visión compartida. Este nivel posee dos sustitutos.

El primer sustituto consiste en implementar una estructura de aprendizaje organizacional institucionalizada. El conocimiento se encuentra en repositorios no humanos tales como las rutinas, los sistemas, las estructuras, la cultura y la estrategia, conocimiento que evoluciona continuamente en los individuos, grupos, y organización, que construye los procesos de formulación e implementación de la estrategia de una empresa centrada en la lectura del medio ambiente. El segundo sustituto implica la elaboración de la estrategia a nivel de unidades funcionales y de negocio, que viene de expertos a quienes se les traslada el foco de las responsabilidades estratégicas.

Sustituto de liderazgo nivel sociedad, está estrechamente ligado a la gestión efectiva de la red de grupos de interés, que resulta en organizaciones más éticas y con viabilidad de largo plazo. Un liderazgo de este tipo orienta decisiones y procesos que busquen atender y equilibrar las relaciones con los stakeholders, desde la estrategia y los requerimientos de rentabilidad; así como respetando las relaciones y valor intrínseco de los intereses de las partes involucradas. El resultado, restablecer la confianza en el entorno empresarial (Academy of Management Annual Meeting Proceedings, 2011).

En síntesis, el liderazgo transaccional se dedica a alinear las motivaciones extrínsecas de los colaboradores con la organización a través del refuerzo contingente y en algunos casos por la dirección activa o pasiva por excepción; por otro lado, el liderazgo transformacional se preocupa por las demandas de los colaboradores a fin de obtener su confianza, alineando sus intereses con los del líder; mientras que el liderazgo trascendente se ubica en un momento más evolucionado de la historia, "respondiendo a una llamada planetaria para un proceso de gobernabilidad más inclusivo, más confiado en 
el otro, con más intercambio de información (que está sucediendo de todas formas a través de Internet), con la participación más significativa de los involucrados (casi todo menos "seguidores") [...]" (Gardiner, 2006:11). Este liderazgo "no excluye a las personas inconformistas, visionarias o con un especial carisma. Al contrario, estas cualidades podrán impulsar aún más su liderazgo, siempre y cuando el líder ponga sus cualidades o su carisma al servicio de los demás" (Cardona, 2009:49).

\section{Discusión}

Se considera importante analizar la incidencia de la dinámica relacional en los modelos de liderazgo contemporáneos descritos, mediante la respuesta a la siguiente interrogante: ¿Cómo incide la dinámica relacional en los modelos de liderazgo contemporáneo, y cómo estos enfoques teóricos encajarían en las organizaciones de la Economía Popular y Solidaria? ${ }^{3}$.

Las raíces ideológicas de la economía popular y solidaria se reconocen en la economía social, disciplina que recurre a Robert Owen, Saint Simon, entre otros, precursores del socialismo utópico y asociacionista, hacedores a la vez del cooperativismo y mutualismo, movimientos esenciales vigentes en la construcción de las sociedades modernas, con visiones de producción humanizadas. El concepto de economía social se acuñó en Francia, a fines del primer tercio del siglo XIX, por liberales como Dunoyer (1830) y F. Passy; los socialistas Pecqueur, F. Vidal y B. Malon, el social cristiano F. Le Play y solidaristas como A. Ott. Este concepto de economía social que no tiene equivalencia más que en la lengua española, como "Economía solidaria", "Economía popular y solidaria", "Economía del trabajo", "Economía alternativa”, "Economía asociativa", "Economía participativa", "Sector Voluntario", "Sector no lucrativo", etc.

El concepto de economía social, quiere hacer desaparecer la dicotomía entre "hombre económico - hombre social”. Monzon (1992) concibe la economía al servicio del hombre y de la sociedad, armonizando las dimensiones social e individual, y pretende conectar los problemas económicos con el entorno natural-ecológico, ampliando la visión centrada en la problemática de la asignación de recursos de la economía ortodoxa hacia los conflictos relativos a la distribución, condiciones de producción, desempleo, pobreza y calidad de vida (Salminis, 2004: 2). En Francia la "Charte de l'économie sociale» define economía social como el conjunto de entidades no pertenecientes al sector público, que, con funcionamiento y gestión democráticos e igualdad de derechos y deberes de los socios, practican un régimen especial de propiedad y distribución de las ganancias, empleando los excedentes del ejercicio para el crecimiento de la entidad y mejora de los servicios a la comunidad (Jefatura del Estado Español, 2011: 1).

En lo que tiene que ver con la Economía Social y Solidaria, América Latina ha logrado institucionalizarla en algunos países, incluso en solo gobiernos autónomos, como es el caso de Mendoza en Argentina. En 1984, Honduras dictó una Ley del Sector Social de la Economía; en 1998, Colombia sancionó la Ley 454 por la cual se regula la Economía Solidaria; Venezuela también lo hizo en el año 2012 y en México se dictó en 2012 la Ley de Economía Social y Solidaria, reglamentaria del artículo 25 de la Constitución Política. Bolivia dictó su ley en el año 2013. Sin embargo las legislaciones que involucran a todas las formas de organización 
En este contexto, considerando que el liderazgo relacional se caracteriza por la interacción entre el líder y colaboradores, que pueden constituirse en pares, equipo e incluso subordinados, con prácticas de cultura organizacional y de estrategia sinérgicas; interacciones entre líder y organización de base; líder y partes interesadas; y, con propósitos de entender en qué consiste la dinámica relacional, esta discusión identifica cuáles son los elementos constitutivos de dicha dinámica, luego explica en qué consiste la dinámica y su incidencia en los enfoques de liderazgo transaccional, transformador y trascendente concebidos en este documento como liderazgos relacionales.

En cuanto a los elementos constitutivos de la dinámica relacional se identifican las relaciones de influencia y las relaciones de intercambio. Se adopta a Cardona (2000) para explicarlas.

Relaciones de influencia. Correspondencia vinculante, potestativa, deseada entre el líder y los sujetos intervinientes en la organización, como un proceso en el cual el líder ejerce "poder no coercitivo" con propósitos de lograr los objetivos institucionales de manera voluntaria. Se plantea una relación en la que hay influencia mutua entre el líder y actores. Es un acercamiento dinámico, contrario a los modelos de liderazgo tradicionales. Existe una necesidad dependiente entre sujetos intervinientes.

Relaciones de intercambio. Entendimiento de necesidades mutuas entre el líder y actores implicados con la organización, como proceso transaccional que busca satisfacer necesidades de tipo económico y de carácter social, relacionadas al trabajo y la contribución, originando relaciones de intercambio económico y relaciones de intercambio social. El intercambio económico está basado en acuerdos de naturaleza explícitas y el intercambio social en acuerdos implícitos que pueden ser entendidos como compromisos y desarrollo conjunto.

Dinámica relacional. Explica el intercambio que se conforma por lógicas de transacción e influencia entre los actores involucrados; el punto de inequidad puede darse en cuanto a una distribución de poder asimétrica: el líder tiene mayor capacidad de influencia. Sin embargo, en algunas organizaciones como las que pertenecen a la Economía Popular y Solidaria ${ }^{4}$, se cree que esta inequidad debe tender a desaparecer, para que sustente la intención primigenia de este tipo de organizaciones:

de economía social, se establecen por primera vez en España con la Ley de Economía Social, marzo de 2011, y en Ecuador, la LOEPS, abril de 2011, pues las leyes conocidas hasta ese año, se refieren separadamente al cooperativismo o a la economía social, es decir su tratamiento normativo en conjunto, como parte integrante de un mismo sector de la economía, con características y esquemas doctrinarios similares se dan en estos dos países.

4 Se adapta el concepto de liderazgo en emprendimientos sociales al liderazgo en la economía popular y solidaria, que se entenderá como "la capacidad para hacer transformaciones y obtener 
[...] forma de organización económica, donde sus integrantes, individual o colectivamente, organizan y desarrollan procesos de producción, intercambio, comercialización, financiamiento y consumo de bienes y servicios, para satisfacer necesidades y generar ingresos, basadas en relaciones de solidaridad, cooperación y reciprocidad, privilegiando al trabajo y al ser humano como sujeto y fin de su actividad, orientada al buen vivir, en armonía con la naturaleza [...] (Asamblea Nacional, 2011: Art.1).

resultados sobresalientes" (Banco Interamericano de Desarrollo, 2006:35). Según el mismo BID (2006), no existe un estilo de liderazgo eficiente y eficaz para todas las organizaciones, sin embargo considera que algunos roles que el líder debe asumir se adaptan mejor, según los desafíos de gestión que deba afrontar, en relación a la etapa de crecimiento en que se encuentre la organización,

...al inicio del emprendimiento social, la tarea se facilita enormemente con un líder que tenga influencia personal, de tipo carismático. Después, durante la institucionalización, es ventajoso un liderazgo directivo; conviene que sea participativo en la etapa de descentralización, y político cuando se alcanza el conglomerado social. No obstante, sea cual fuere el estilo de gestión, lo importante es que la organización obtenga un buen desempeño en el emprendimiento social (Social Enterprise Knowledge Network y Harvard University, 2006:37).

...organizaciones entrevistadas cuentan con una estructura organizacional muy similar, por lo general son organigramas verticales conformados en primera instancia por un presidente, seguido de una Junta Directiva, un Gerente General y un Equipo Ejecutivo subdividido por áreas o coordinaciones. Esto coincide con el estudio realizado por el BID y SEKN (2006), donde en el 95\% de las OSC investigadas predomina claramente una estructura organizacional que agrupa en dos grandes áreas a sus "direcciones" o "coordinaciones". La primera está referida al conjunto de programas o servicios centrales ofrecidos por la organización y la segunda contiene las áreas administrativas o de gestión que apoyan tanto a los otros órganos de línea como a la institución en su conjunto (Radrigán, 2012).

El estudio de Radrigán (2012) en Chile indica que las instancias internas planifican, toman decisiones sin eximir la participación grupal en estos procesos.

El liderazgo que se da al interior de estas organizaciones presenta diversas perspectivas: una perspectiva externa donde las organizaciones se tienen que coordinar con los usuarios o clientes del servicio que prestan, al igual que con los voluntarios; y una perspectiva interna, donde las personas vinculadas laboralmente desarrollan un liderazgo colectivo, cada profesional posee la dirección de un área determinada, y esto permite la existencia de un diálogo entre pares (Radrigán, 2012:158).

La relativización de la investigación en el sector de la economía popular y solidaria deriva en pocos estudios que predigan con alta certeza la realidad del liderazgo en el sector, no obstante estudiosos revalorizan aspectos como "la conveniencia de la 'selección de los directivos', y por tanto, desde una perspectiva prescriptiva en los factores o procesos que podrían coadyuvar a 'fabricar' Directivos de la Economía Social, en teoría el recurso humano estratégico" (Chaves \& Sajardo, 2004:49), óptimo para este tipo de organizaciones. Otros al respecto mencionan que las “...organizaciones estudiadas consideran que poseen un liderazgo democrático, el que está basado en el diálogo y en los equipos de trabajo que canalizan las percepciones y opiniones presentes en las diversas áreas" (Radrigán, 2012:159). 
Esta dinámica da origen al liderazgo relacional que produce flujos de transacción e influencia-dinamismo- que oscilan entre incentivos económicos y sociales.

Los incentivos económicos se centran en los acuerdos de carácter formal -explícitosque norman o regulan actividades entre el líder y algunos de los actores intervinientes, como los pares, equipos, subordinados, la comunidad. Un ejemplo de ello son las rutinas organizacionales que deben ser acatadas en una lógica de estímulo-respuesta por el subordinado.

Por otro lado, los incentivos sociales giran en torno a relaciones y dinámicas, son de carácter implícito, se diferencian de los económicos al no establecer actividades específicas. No existe una norma que obligue al cumplimiento de acciones formales sino por el contrario, éstas se realizan por compromiso entre actores hacia la consecución de objetivos comunes.

Cardona (2000) en un principio menciona que cualquiera de estas formas de relaciones es excluyente - de suma cero- en referencia a que puede presentarse una sola de ellas como rasgo específico en las dinámicas de liderazgo; o bien un colaborador cumple por convicción (relación social) o lo hace por condicionamiento (recompensa - castigo).

Con relación a los tipos de liderazgo relacional, este mismo autor hace referencia: "La mayoría de los modelos de liderazgo relacional se han basado en la teoría tradicional de relaciones de intercambio, según la cual la relación entre líder y colaborador es de tipo económico o de tipo social" (Cardona, 2000:6). Al respecto, Burns (1978), citado por Castro Solano (2007); postuló una teoría acerca del liderazgo transformacional. Esta entiende al liderazgo como un proceso de influencia en el cual los líderes influyen sobre sus seguidores. Los líderes asimismo resultan afectados, modificando sus conductas si perciben respuestas de apoyo o resistencia por parte de sus adeptos (Castro Solano, 2007:216).

[...] Burns establece, además, una diferenciación entre el liderazgo transformacional y el denominado liderazgo de tipo transaccional. En el primer caso, se trata de un proceso en el cual se establece una relación transformadora en la que el líder hace de catalizador del cambio organizacional, transformando a los miembros del grupo; en cambio en el liderazgo transaccional se establece un proceso en el cual la relación de liderazgo supone un intercambio, que puede ser tanto económico como psicológico, entre la figura del líder y los miembros del grupo, de modo que ambos salgan beneficiados de dicha transacción (Castro Solano, 2007:216). 
Con relación al liderazgo trascendente, Cardona (2000) lo define como una relación de influencia de contribución. En esta relación, el colaborador interactúa con el líder por motivación extrínseca e intrínseca.

[...] A pesar de que en el liderazgo relacional, el elemento que define la relación de influencia es el tipo de motivación del colaborador, el comportamiento del líder sigue siendo un elemento crítico en la relación, pues puede afectar a las motivaciones que llevan al colaborador a mantener la relación (Cardona, 2000:7).

Gráfico 2. Caracterización del liderazgo relacional.

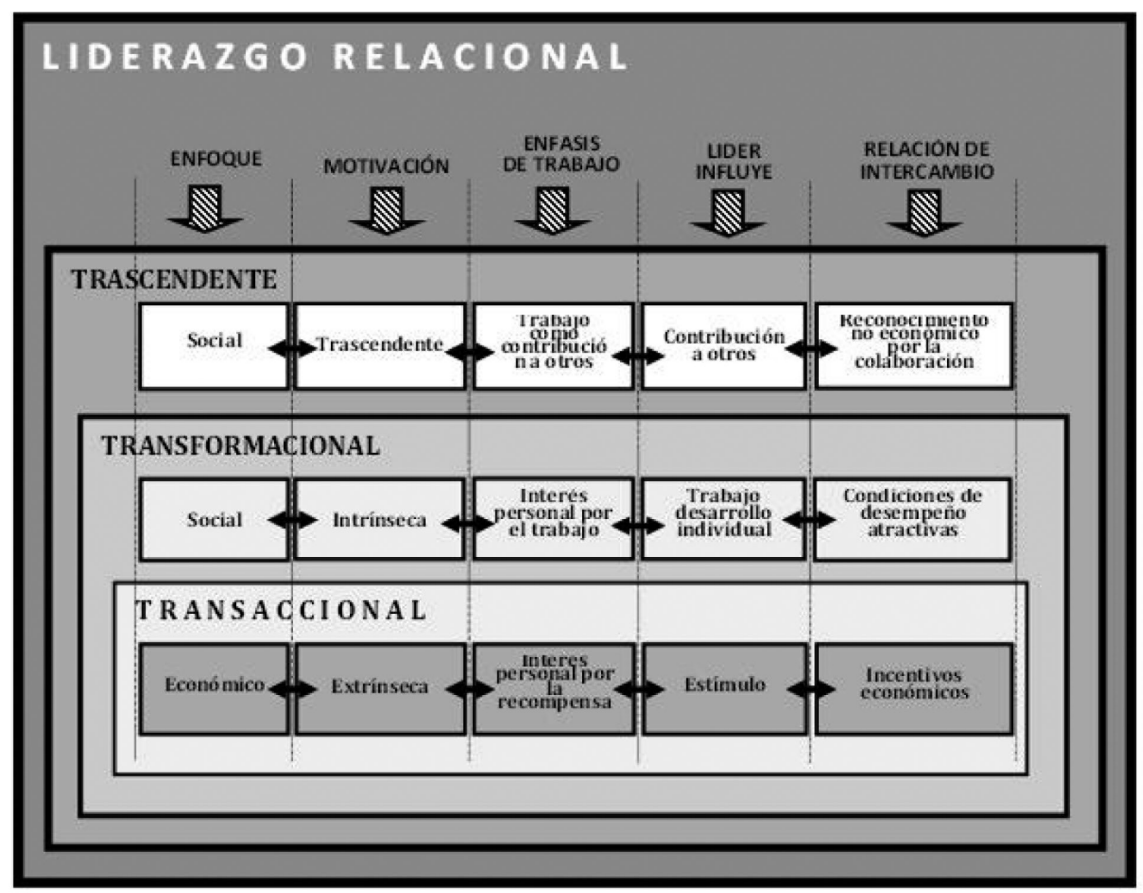

Fuente: elaboración propia.

El surgimiento del liderazgo relacional incluye, en la dinámica, la cultura y aprendizaje organizacional, normas del contexto, responsables de estrategia y se determina que las tres formas de enfoque relacional -económico, de trabajo y contribución- son complementarias, de carácter incremental, se soportan una a las otras.

Comprender la dinámica relacional, conlleva además tomar en cuenta el punto de vista de la motivación humana, Pérez López (2006) menciona que los motivos extrínsecos, que se refieren a interacciones generadas por el intercambio basado en la satisfacción económica; los intrínsecos, que se caracterizan cuando en la actuación del individuo 
prevalecen las satisfacciones personales sin necesidad de recibir incentivos externos; y de tipo trascendente, que están caracterizados por la importancia que el sujeto otorga a las consecuencias, repercusiones y aprendizajes que su actuación tiene sobre los demás. Estos tres tipos de motivación guían la conducta individual hacia los objetivos de la organización.

En este sentido, Pérez López (1998) alude que los motivos de la acción de una persona pueden corresponder al logro de ciertos resultados específicos -extrínsecos, acción y reacción del entorno; intrínsecos, satisfacción sujeta a la propia ejecución de la acción; reacción del entorno sobre la ejecución de la acción y sus consecuencias en él- que conciernan a cualquiera de estas categorías de acción, como motivos de decisión -aun si el ente involucrado no tuviera conciencia de ellas-, los sujetos siempre tendrán en cuenta estos tres tipos de resultados. Siguiendo esta línea de pensamiento, "la motivación de una persona para realizar una acción puede ser conceptualizada como el atractivo que le impulsa a realizarla, dado el valor que el sujeto alcanza al ponerla en práctica” (Pérez López, 1998:45).

"La persona humana es esencialmente un ser social"...que está abierto a los demás, no sólo a causa de sus posibles preferencias altruistas, sino también porque necesita de los demás, no sólo para satisfacer sus necesidades (extrínsecas y resultados intrínsecos), sino también para crecer como persona (intrínseca y resultados trascendentes). La sociedad no es un artefacto para la mejora de la satisfacción de las personas, pero es esencial para la identidad, la auto-comprensión y el desarrollo del individuo. (Argandoña, 2012:11).

Para hacer el análisis del cómo llegan a influir las motivaciones en los actores de una organización eminentemente social, la motivación trascendente marca la pauta, porque tanto la "motivación espontánea por motivos trascendentes (que llamaremos motivación trascendente) como su motivación racional por motivos trascendentes (que denominaremos motivación intrínseca estructural)" (Pérez López, 2006:168) despliega la 'racionalidad' y la 'virtualidad' que han sido utilizadas para desarrollarla y aplicarla en estas organizaciones.

El factor distintivo de esta motivación es que con su acción busca satisfacer necesidades ajenas, no propias. A esta motivación nos referimos cuando hablamos de generosidad, espíritu de servicio, impacto en la sociedad, responsabilidad social, etc. El emprendimiento social entraría dentro de este grupo de motivaciones. (Hernández, 2013:15).

Comentando a Hernández (2013), se cree que esta motivación trascendente se sostiene en varias evidencias empíricas, en donde se visualiza a un ser humano no siempre indiferente de las necesidades de otros seres humanos; para estas personas el valor percibido difiere notablemente del valor real, aun a pesar de su naturaleza voluble e inestable, porque de 
una adecuada educación afectiva, se logrará en los actores sentimientos de felicidad por el crecimiento personal y la motivación de participar en organizaciones que se preocupan por su desarrollo sustentable y el de sus congéneres; estas aseveraciones llevan ineludiblemente a identificar que tanto el líder como los actores comprometidos con las organizaciones actúan por motivación trascendente, que promueve el liderazgo del mismo nombre, que optimiza el talento de quienes actúan en la organización para lograr el bienestar o el "buen vivir" inclusivo, confiando en las potencialidades y la participación del otro, en pos del desarrollo social y del desarrollo de la organización social.

No obstante, la motivación extrínseca y la intrínseca juegan un rol decisorio en las organizaciones de la Economía Popular y Solidaria, porque "en circunstancias ideales, el liderazgo de mejor calidad será aquél que logre la mejor combinación de los tres tipos de liderazgo, de acuerdo a la realidad a la que ha de liderar" (Hernández, 2013:15).

Para acotar a este análisis, se aborda la motivación extrínseca como:

...aquel tipo de fuerza que empuja a la persona a realizar una acción debido a las recompensas (o castigos) unidos a la ejecución de la acción; es decir, debido a la respuesta que va a provocar dicha acción desde el exterior. Así pues, lo verdaderamente querido no es la realización de la acción de que se trate, sino las recompensas. La ejecución de la acción viene a ser una condición impuesta desde el exterior para que la persona alcance aquello que en el fondo le motiva y que a su vez responde a la voluntad de la persona que motiva. (Hernández, 2013:14).

"La motivación intrínseca: la parte o componente de la motivación debida al deseo del sujeto de la pura ejecución de la acción, es decir, prescindiendo de cuáles puedan ser las consecuencias externas de la acción (resultados internos)" (Pérez López, 1998:45).

Estos dos tipos de motivación se vinculan íntimamente con las relaciones de influencia e intercambio económico y social, entre el líder y los actores de la organización, que pondrían en evidencia un liderazgo transaccional y transformacional, respectivamente.

Resumiendo, estos tipos de motivación, dependiendo del interés que generan en los actores, contribuyen al establecimiento de relaciones de influencia e intercambio que dan origen a los tres enfoques teóricos de liderazgo relacional, beneficiosos en el ámbito de la disciplina de la Economía Popular y Solidaria, en razón a que se plantea como hipótesis que en ella se pueden encontrar formas de liderazgo básicas como las transaccionales, o con un denotado progreso como las transformacionales y, las más evolucionadas, con relaciones de influencia, intercambio y contribución, acordes al entorno de relaciones simétricas entre actores, en donde el líder mantiene vinculaciones verticales -hacia arriba y hacia abajo-, nexos horizontales entre 
pares y equipos; y relaciones transversales con el entorno, a quienes responden con resultados efectivos y oportunos.

\section{Bibliografía}

Academy of Management Annual Meeting Proceedings (2011). "Towards an expanded model of transcendent leadership: substitutes and the societal level". Business source premiere, pp. 1 - 6.

ACI (2013). Principios y valores cooperativos. [En línea] [Último acceso: 21 diciembre 2013]. Available at: http://www.aciamericas.coop/Principios-y-ValoresCooperativos-4456.

Alianza País (2014). La economía popular y solidaria crea el 60\% del empleo en Ecuador. [En línea] [Último acceso: 22 febrero 2014]. Available at: http://www. movimientoalianzapais.com.ec/index.php?option=com_content\&v iew=article\&id=8266:laeconomiapopularysolidariacreael60-delemp leoenecuador\&catid $=55 \&$ Itemid $=260$.

Asamblea Nacional (2008). Constitución de la República del Ecuador. [En línea] [Último acceso: 6 enero 2014]. Available at: http://www.asambleanacional.gov. ec/documentos/constitucion_de_bolsillo.pdf.

Asamblea Nacional (2011). Ley Orgánica de Economía Social y Solidaria y del Sector Financiero Popular y Solidario. s.l.:s.n.

Ascorra Costa, P. (2008). "Liderazgo: de la posición a la relación. Una propuesta de análisis de los modelos teóricos y sus aplicaciones al contexto administrativo chileno". Psicoperspectivas, Volumen VII, pp. 60-75.

Banco Interamericano de Desarrollo (2006). Gestión efectiva de emprendimientos sociales: lecciones extraidas de empresas y organizaciones de la sociedad civil en Iberoamérica / Social Enterprise Knowledge Network. Primera ed. Washington DC: Editorial Planeta Mexicana S.A. de C.V., p. 351.

Cardona, P. \&. R. C. (2009). "El liderazgo centrado en la misión". Harvard Deusto business review, p. 46.

Cardona, P. (2000). “Liderazgo relacional”. IESE, Universidad de Navarra. [En línea] [Último acceso: 3 marzo 2014]. Available at: http://repositorio.cucea.udg. mx:8080/jspui/handle/123456789/108.

Castro Solano, A. (2007). Estilos de liderazgo, inteligencia y conocimiento táctico. Editorial Paidós SAICF. Anales de Psicología, 23(2), p. 296.

Cetina, T.; Ortega, I. \& Aguilar, M. (2010). "Habilidades directivas desde la percepción de los subordinados: Un enfoque relacional para el estudio del liderazgo". Psicoperspectivas, 9(1), p. 126. 
Chaves, R. \& Sajardo, A. (2004). "Economía política de los directivos de las empresas de economía social". CIRIEC-España, Revista de Economía Pública, Social y Cooperativa, abril, Issue 48, pp. 31-52.

Coraggio, J. L. (2002). "La economía social como vía para otro desarrollo social". s.l.:s.n.

Crossan, M.; Vera, D. \& Nanjad, L. (2008). "Transcendent leadership: strategic leadership in dynamic environments". Leadership Quarterly, p. 569.

D’Alessio, F. (2010). Liderazgo y atributos gerenciales: Una visión global y estratégica. México: Prentice Hall-Pearson Education, p. 472.

García Rubiano, M. (2011). "Liderazgo transformacional y la facilitación dela aceptación al cambio organizacional”. Pensamiento Psicológico, pp. 41 - 54. Bogotá. [En línea] Available at: http://revistas.javerianacali.edu.co/javevirtualoj/index.php/ pensamientopsicologico/article/view/164.

Gardiner, J. J. (2006). "Transactional, transformational and transcendent leadership: metaphors mapping the evolution of the theory and practice of governance". Leadership Review, Volumen 6, p. 62.

Hernández, P. A. (2013). "El talento como factor diferenciador de la acción de emprender", Madrid: s.n.

IEPS (2011). "Quienes somos”. [En línea] [Último acceso: 22 febrero 2014]. Available at: http://www.ieps.gob.ec/web/index.php?option=com_content\&view=a rticle\&id=39\&Itemid $=231$.

Jefatura del Estado Español (2011). "Ley 5/2011, de 29 de marzo, de Economía Social”. s.l.:s.n.

Lizarzaburo, G. (2013). "Economía popular y solidaria aporta el 13\% del PIB y genera el 64\% de empleo a nivel nacional". Agencia de Noticias de Ecuador y Suramerica. "Andes", 23 enero.

Lupano Perugini, M. L. \& Castro Solano, A. (2005). "Estudios sobre el liderazgo. Teoría y evaluación”. Psicodebate 6, Psicología, Cultura y Sociedad, p. 108.

Lussier, R. \& Achua, C. (2011). "Liderazgo: teoría, aplicación y desarrollo de habilidades". México: CENGAGE.

Marco Perles, G. S. (2000). “Papeles de ética, economía y dirección”, no 5, 2000. s.l.: s.n.

Martínez Valle, L. (2009). “La economía social y solidaria. ¿'Mito o realidad?”. Iconos. Revista de Ciencias sociales, Mayo, Volumen 34, pp. 107-113.

Palomo, M. T. (2012). Liderazgo y motivación de equipos de trabajo. Séptima Edición. Madrid: ESIC Editorial. 
Pérez López, J. A. (1993). Fundamentos de la dirección de empresas. $5^{\circ}$ edición ed. Madrid: Rialp. p. 260.

Pérez López, J. A. (1998). Liderazgo y ética en la dirección de empresas. La nueva empresa del siglo XXI. Primera Edición. Ed. Bilbao: Ediciones Deusto, S.A. p. 240.

Pérez López, J. A. (2006). Fundamentos de la dirección de empresas. Sexta edición ed. Madrid: Ediciones RIALP, S.A. p. 280.

Radrigán, M. (2012). "Gestión y Liderazgo en los emprendimientos sociales: el caso del sector no lucrativo chileno". Polis, Revista de la Universidad Bolivariana, pp. 141-165.

República del Ecuador - Asamblea Nacional (2011). Ley Orgánica de la Economía Popular y Solidaria y del Sector Financiero Popular y Solidario. Quito: s.n.

Rice, P. (1997). Desarrollo humano: Estudio del ciclo vital. México: Pearson Prentice Hall. Ruiz Palomino, P. (2009). "Documento de trabajo Seminario Permanente de Ciencias Sociales”. [En línea] [Último acceso: 7 marzo 2014]. Available at: http:// www.uclm.es/CU/csociales/pdf/documentosTrabajo/2009/05.pdf.

Salminis, J. (2004). "Significados, alcances y perspectivas del Sector de la Economía Social”. s.l., s.n.

SEPS (2012a). Preguntas frecuentes. [En línea] [Último acceso: 21 diciembre 2013]. Available at: http://www.seps.gob.ec/web/guest/faqs.

SEPS (2012c). Boletin de Coyuntura $N^{\circ} 1$ - El Sector Económico Popular y Solidario en Ecuador. [En línea] [Último acceso: 14 enero 2014]. Available at: http:// www.seps.gob.ec/c/document_library/get_file?uuid=22db6c327709-4c72-b12e-0de1b168cb5b.

SEPS (2012e). ¿Quées la SEPS? [En línea] [Último acceso: 21 febrero 2014]. Available at: http://www.seps.gob.ec/web/guest/que_es_la_seps.

SEPS (2012f). Sector Cooperativo. [En línea] [Último acceso: 22 febrero 2014]. Available at: http://www.seps.gob.ec/web/guest/sector-cooperativo

SEPS (2013). Boletín Trimestral I - Un vistazo del sector cooperativo por segmentos y niveles. [En línea] [Último acceso: 22 febrero 2014]. Available at: http:// www.seps.gob.ec/c/document_library/get_file?uuid=31a2df8b255f-4a50-8d2d-1174b22d366b.

Social Enterprise Knowledge Network y Harvard University (2006). Effective Management of Social. United States of America: Library of Congress Cataloging-in-Publication Data. Primera ed. Washington DC, p. 351.

Superintendencia de Economía Popular y Solidaria (2012). Boletín de Coyuntura $N^{\circ}$ 1, s.l.: s.n. 
Universidad Nacional de Tres de Febrero. Lic Pablo Levinton, 2013. Clase 6 parte 1: Historia y doctrinas del cooperativismo, s.l.: s.n.

Weber, M. (2007). Sociología del poder: los tipos de dominación. Madrid: Alianza.

\section{Cómo citar este artículo:}

Sánchez, S. et al. (2014). “Teorías de liderazgo contemporáneo: análisis de la dinámica relacional”, Oikos No 37, 41 - 61, Escuela de Administración y Economía, Universidad Católica Silva Henríquez (UCSH), Santiago de Chile. [http://ediciones.ucsh.cl/revistas.php]

Fecha de recepción: 17 / 06 /2014

Fecha de aceptación: 14 / 11 / 2014 